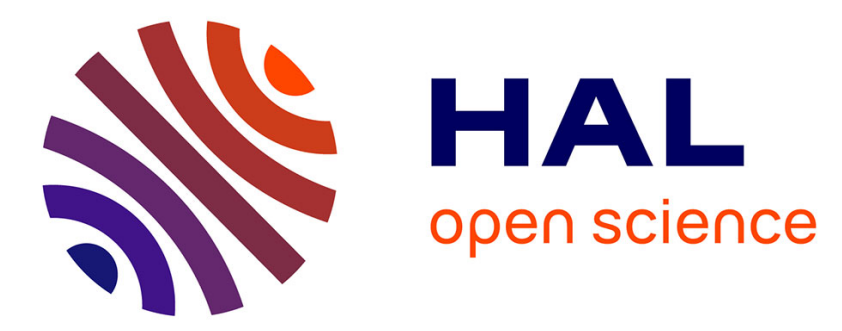

\title{
EVALUATION OF THE REMOVAL OF POINT OF SALE TOBACCO DISPLAYS IN IRELAND
}

Ann Mcneill, Sarah A Lewis, Casey Quinn, Maurice Mulcahy, Luke Clancy, Gerard Hastings, Richard Edwards

\section{- To cite this version:}

Ann Mcneill, Sarah A Lewis, Casey Quinn, Maurice Mulcahy, Luke Clancy, et al.. EVALUATION OF THE REMOVAL OF POINT OF SALE TOBACCO DISPLAYS IN IRELAND. Tobacco Control, 2010, 20 (2), pp.137. 10.1136/tc.2010.038141 . hal-00586595

\section{HAL Id: hal-00586595 https://hal.science/hal-00586595}

Submitted on 18 Apr 2011

HAL is a multi-disciplinary open access archive for the deposit and dissemination of scientific research documents, whether they are published or not. The documents may come from teaching and research institutions in France or abroad, or from public or private research centers.
L'archive ouverte pluridisciplinaire HAL, est destinée au dépôt et à la diffusion de documents scientifiques de niveau recherche, publiés ou non, émanant des établissements d'enseignement et de recherche français ou étrangers, des laboratoires publics ou privés. 
Confidential draft - not to be cited to quoted

\section{EVALUATION OF THE REMOVAL OF POINT OF SALE TOBACCO PROMOTIONAL DISPLAYS IN IRELAND}

Ann McNeill, PhD

Professor of Health Policy \& Promotion

UK Centre for Tobacco Control Studies

Division of Epidemiology \& Public Health

University of Nottingham. England, UK

Sarah Lewis PhD

Professor of Medical Statistics

UK Centre for Tobacco Control Studies

Division of Epidemiology \& Public Health

University of Nottingham, England, UK

Casey Quinn, $\mathrm{PhD}$

Lecturer in Health Economics

Division of Primary Care

School of Community Health Sciences

University of Nottingham, England, UK

Maurice Mulcahy

Area Chief Environmental Health Officer

Health Service Executive, Ireland

Luke Clancy MD

Director General \& Professor of Respiratory Medicine

Research Institute for a Tobacco Free Society

Dublin, Ireland

Gerard Hastings PhD

Professor of Social Marketing

UK Centre for Tobacco Control Studies

University of Stirling, Scotland, UK

Richard Edwards MD

Professor of Public Health

Department of Public Health

University of Otago

Wellington, New Zealand

Corresponding author

Ann McNeill

ann.mcneill@nottingham.ac.uk 
Confidential draft - not to be cited to quoted

\section{Abstract}

Aim:

To evaluate the short-term impacts of removing point of sale promotional displays in Ireland, implemented in July 2009.

Methods:

Retailer compliance was assessed using audit surveys in 2007, 2008 and 2009. Using a monthly survey of 1000 adults carried out since 2002, changes in smoking prevalence were assessed; attitudes were measured using extra questions added for a ten month period before and after the law. Youth responses were assessed using a cohort of 180 13-15 year olds, interviewed in June and August 2009.

Results:

Immediately following implementation, compliance was 97\%. Support for the law increased among adults after implementation (58\% Apr-Jun vs 66\% Jul-Dec, p $<0.001$ ). Recall of displays decreased significantly for adults ( $49 \%$ to $22 \%$; $\mathrm{p}<0.001$ ), more so among teenagers ( $81 \%$ to $22 \%$; $\mathrm{p}<0.001)$. There were no significant short term changes in prevalence among youth or adults. The proportion of youth believing more than a fifth of children their age smoked decreased from $62 \%$ to $46 \%, \mathrm{p}<0.001$ ). Post legislation, $14 \%$ of adult smokers thought the law had made it easier to quit smoking and $38 \%$ of teenagers thought it would make it easier for children not to smoke.

Conclusions:

Compliance was very high and the law was well supported. Recall of displays dropped significantly among adults and teenagers post legislation and there were encouraging signs that the law helped denormalise smoking. 
Confidential draft - not to be cited to quoted

\section{Introduction}

Point of sale promotional displays (displays of tobacco and advertising and promotion at the point of sale or purchase) remain one of the main channels for tobacco marketing following the implementation of bans on advertising. [1,2] In many countries such as the UK, there is extensive involvement of the tobacco industry in maintaining displays which have grown in prominence and size in recent years, and are frequently found behind cashiers, near sweets and in ways that obscure health warnings.[3,4] Tobacco promotions at point of sale have also been found to be higher among stores close to schools and in more deprived neighbourhoods.[5-7] The importance of point of sale for marketing and the resources utilised for this purpose is spelt out clearly in tobacco industry documents.[1,8,9] Research has shown that smokers rarely use point of sale displays in deciding which brand of tobacco to purchase, with one study indicating that only $1 \%$ of smokers always, and less than $10 \%$ sometimes, decided which brand of tobacco to purchase at the point of sale.[10] However, point of sale displays can act as cues to purchase tobacco; studies have shown that between 10 and $25 \%$ of smokers report that they stimulate unplanned or impulse purchases of cigarettes with some indication that younger smokers may be more likely to notice cigarette displays and make impulse purchases.[11,12] These studies also showed that significant proportions of smokers agree that removing tobacco displays would make it personally easier not to smoke and help to maintain the resolve not to smoke when attempting to quit, a finding supported by qualitative research with smokers in New Zealand.[13] A recent systematic review found strong evidence that point of sale promotional displays increased susceptibility to smoking and uptake of smoking among youth, and concluded that their removal was warranted.[14] This conclusion is supported by recent longitudinal research with schoolchildren.[15]

Over recent years, Ireland has been at the forefront of tobacco control internationally [16], in particular, being the first country to introduce national comprehensive smoke free legislation in 2004. On 1 July 2009, Ireland removed point of sale tobacco advertising and displays through further provisions of its Public Health (Tobacco) Acts 2002 to 2009, becoming the first country in the European Union to do so, but following similar legislation in Iceland, Thailand, and some provinces and territories in Canada. The legislation prohibited advertising of tobacco products in retail premises and mandated the tobacco products must be stored out of view of customers. It also prohibited vending machines except in licensed premises and registered clubs (in accordance with Regulations), and that all persons selling tobacco products by retail had to register with the Office of Tobacco Control (OTC).

There has been very little in the peer reviewed literature assessing the impact of point of sale removal. This study reports the findings of a multifaceted evaluation focusing on the removal of the tobacco point of sale displays in the Irish legislation, the process of implementation and on the short term impacts of the legislation. Impact on tobacco sales are reported in a separate paper. [17]

\section{Methods}

We developed a logic model (Figure 1) with process and outcome indicators to underpin and 
Confidential draft - not to be cited to quoted

structure the evaluation, adapted from similar models developed elsewhere. [18,19] Data sources were identified following literature searches and discussions with funders, stakeholders and academics in Ireland. Extensions to existing data gathering were commissioned to fill some of the identified gaps, but the extent of this was limited by financial and time constraints. We extracted and analysed relevant data from each source.

\section{--Figure 1 about here--}

Sources of evidence

Document research

Irish websites and legislation were searched to describe contextual information, the process of introduction and implementation of the regulations, enforcement and communication strategies.

\section{Retail audit surveys}

Compliance with the legislation was measured using data from three retail audits commissioned by the OTC in Ireland and carried out annually in July and August in 2007, 2008 and 2009 by Ipsos mrbi with quota samples of 1309, 1203 and 1209 retail outlets, respectively. These outlets were visited by two researchers, including one minor (aged from 14 to 17 years old) who attempted to purchase cigarettes using a standardised protocol to ascertain sales to under 18 year olds. The adult researcher was responsible for carrying out a visual inspection of the premises to assess for the presence, nature and location of tobacco advertising and tobacco product displays in stores.[20-22]

\section{Adult surveys}

Since July 2002, OTC has commissioned a monthly omnibus telephone survey conducted by Ipsos mrbi. Random digit dialing is used to identify over 1000 participants each month and a stratified quota sampling approach is utilised whereby quotas are set by gender, age, social class (using A,B,C1,C2,D,E occupational groupings [23]) and region to achieve a representative sample of the Irish population over 15 years of age. These surveys (to July 2010) were used to assess any changes in adult cigarette smoking prevalence in the 12 months following the legislation. From April 2009, for a period of 10 months, three questions were added to assess recall of, and views on tobacco displays and their removal (Table 1).

\section{Youth surveys}

Ipsos mbri also carried out two youth surveys before and after the legislation. Face-to-face, in-home interviewing was conducted among 214 Irish teenagers aged 13-15 years, following parental permission, in June 2009. The survey used stratified random sampling based on four regions (Dublin, Rest of Leinster, Munster and Ulster), with quotas set for age, gender and social class (of parental occupation, [23]) to ensure the survey participants reflected the national distribution of children aged 13-15 years in Ireland. In August 2009, the original 214 teenagers were invited for a second interview. At both interviews, questions were asked about smoking, attitudes and the removal of tobacco displays (Table 1). 
Confidential draft - not to be cited to quoted

Table 1 Questions on the tobacco display ban in the adult monthly omnibus survey aged 15+ $(\mathrm{N}=1,000)$ and youth survey $(\mathrm{N}=214$ at baseline and $\mathrm{N}=180$ at follow-up)

Questions

Responses

Timing

Adults and children

In the last month, can you recall seeing any cigarette or tobacco packs displayed

Yes/No/ Don't know

Before \& After

\section{Adults only}

Do you support or do you not support a complete ban on the display of cigarette and tobacco packs inside shops?

Do you think that removing cigarette and tobacco packs from view in shops will make [has made] it easier for smokers to quit smoking or will it make [has it made] no difference? (For smokers only)

\section{Children only}

Do you smoke at all nowadays?

\section{Support/ \\ Do not support/}

Don't Know or no opinion

Will make [Has made] it easier/

Will make [Has made] no

difference/Don't Know

Yes, every day/

Yes, at least once a wk, but not every day/

Yes, less than once a wk/

I used to smoke, but I don't now/

I have never smoked

If you, or someone your age, tried to purchase cigarettes in a shop, do you think you would be successful?

Out of 100 children/classmates your age, how many do you think smoke cigarettes at least once a week?

Do you think that removing cigarette and tobacco packs from view in shops will make it[has made it] easier for young people not to smoke or will it make[has it made] no difference?

And did you say don't know to the last question because you were not aware that cigarette and tobacco products have been removed from view in shops or did you say don't know for another reason?
Will make [has made] it easer/ Will make [Has made] no difference/ Don't Know

0-10/11-20/21-30/31-40/41-50/51-60 /61-70/71-80/81-90/91-100/Don't Know

Yes/No/Don’t Know
Before \& After

Before \& After

Before \& After

Before

[After]

After 


\section{Statistical analysis}

For the adult surveys, we used data weighted to represent the target Irish population in terms of age, gender, social class and region. The changes in the proportions of subjects recalling seeing tobacco displays in shops, supporting a complete ban on tobacco displays, and among smokers, those believing that the legislation to remove displays would make it easier for smokers to stop, were explored by time series plots. For all of these outcomes, the response 'I don't know' was taken as a negative response (we have done this to be conservative, although we acknowledge that some respondents sincerely did not know or selected this response to reflect the fact that they may have mixed feelings about this complex issue). We also combined the data from each of the surveys pre- and post-legislation and used chi-squared tests to determine the statistical significance of changes in responses to each question before and after the legislation. We used an ARIMA interrupted time series analysis to assess whether the introduction of the legislation altered the level or trend in smoking prevalence in the 12 months post-legislation compared to the prior 84 months, after allowing for underlying trends, and autocorrelation.

For the youth survey, participants who responded to both interviews were included in the analysis. We compared the characteristics of these participants with those responding only to the interview pre-legislation, and used weighted data in analysis to match socio-demographic (age, gender, social class and region) characteristics to the general population in Ireland. We defined as current regular smokers those who said "yes" to the question about whether they were smoking one or more cigarettes a week. We categorised perception of the proportion of smokers of their age out of 100 who smoke as $0-20 \%$ (about right), and 21-100\% (overestimate), based on a conservative estimate that around $20 \%$ of Irish teenagers of their age smoked.[24] The proportion of current smokers, perceived success if attempting to purchase cigarettes, proportion overestimating the prevalence of children their age who smoke, recall of seeing tobacco displays and opinions on the effects of the legislation on children's smoking were calculated before and after the legislation, and compared using conditional logistic regression on the paired data. For all outcomes, the response "I don't know" was combined with the response "no" or "no difference" for logistic regression analysis, and measures of effect are presented as odds ratios and $95 \%$ confidence intervals estimated in the conditional logistic regression model.

\section{Results}

Legislation and implementation

The provisions of the Public Health (Tobacco) Act, 2002 pertaining to retail displays and advertising became the subject of a legislative challenge by the tobacco industry (specifically the three main companies in the Irish market: Gallaher [Dublin] Ltd, PJ Carroll and Co. Ltd, and John Player and Sons Ltd) and others, which interrupted the introduction of aspects of the 2002 Act including the point of sale legislation. However on 31 January 2007, six days before the case was about to go into court, the challenge was withdrawn by the plaintiffs who conceded all costs to the state which facilitated the signing of a commencement order in October 2008 to 
give effect to the legislation from 1 July 2009 (SI numbers 404 and 405 of 2009). Prior to this, most forms of tobacco promotion had been prohibited except point of sale tobacco displays and in-store advertisements and promotion. In May 2009 guidance was provided by the Department of Health and Children and OTC[25] indicating that: no advertising of tobacco products was permitted in retail premises; retailers must store tobacco products out of view, within a closed container or dispenser (but not required to be under the counter); retailers could use a pictorial list (in accordance with Regulations) to inform a member of public intending to purchase tobacco as to the products available; and retailers had to display a sign at their premises informing the public that tobacco products could only be sold to persons over 18 years of age. As stated earlier, the legislation also prohibited most vending machines and introduced a registration system for retailers selling tobacco. Enforcement was to be carried out by Environmental Health Officers of the Health Service Executive and if convicted for an offence, the premises to which the conviction related would be suspended from the register of retailers and would not be allowed to sell tobacco for a period defined by the Courts. This was in addition to a fine of up to $€ 3,000$.

Compliance

In 2009, the retail audit found $97 \%$ compliance with the requirement to remove cigarettes out of sight, the $3 \%$ of stores with tobacco on display post-legislation contrasting with $99 \%$ of stores in the audits from 2007 and 2008. Compliance with the legislation varied across type of store, with the chains and larger stores having the highest compliance and smaller independent stores the lowest (95\%) [22]. Similarly, tobacco advertising in the stores visited was virtually ubiquitous in 2007 (92\% of stores) and 2008 (89\%) but had virtually disappeared following the legislation (2\%). Sales to minors, during test purchases attempted during the audits, decreased from $48 \%$ in 2007 , to $40 \%$ in 2008 to $32 \%$ in 2009.

Adult surveys

\section{Point of sale assessment}

The percentage of interviewees who recalled seeing any cigarette or tobacco packs displayed for sale in shops in the last month, dropped from $49 \%$ before to $22 \%$ after the legislation (Percentage reduction in recall of displays post versus pre-legislation $27 \%, 95 \%$ CI $25 \%$ to $29 \%$; $\mathrm{p}<0.001$; Figure 2a). The proportion responding 'don't know' was no more than 5\% across all months and did not vary in any consistent way.

\section{--Figure 2 about here--}

Separate analysis of smokers and non-smokers revealed that smokers were more likely to notice tobacco displays before the legislation (59\% smokers and 46\% non-smokers, $p<0.001$ ); however, after the legislation, smokers were less likely to recall noticing tobacco displays than non-smokers ( $20 \%$ vs $23 \%$ respectively, $p=0.002$ ); Figure $2 a$ ). The effect of the law on recall was therefore greater in smokers than in non-smokers $(\mathrm{p}<0.001)$.

The proportion of people supporting removal of tobacco displays increased from a mean of $58 \%$ in the three months before the legislation to a mean of $66 \%$ in the seven months afterwards 
Confidential draft - not to be cited to quoted

(percentage increase $8 \%, 95 \%$ CI $6 \%$ to $11 \%, p<0.001$ ) (Figure 2b); support was slightly greater in non-smokers than smokers both before (59\% and 54\% respectively; $p=0.008)$ and after $(67 \%$ and $63 \%$ respectively; $p<0.001)$ the law. The data suggest that support for the legislation increased shortly after the legislation and the increase was sustained.

There was a small but statistically significant $(p<0.001)$ fall in the proportion of adult smokers who thought that removal of tobacco displays had made it easier to quit smoking from a mean of $20 \%$ in the three months before to a mean of $14 \%$ in the seven months after the law (percentage decrease $6 \%, 95 \%$ CI $3 \%$ to $10 \%$, Figure $2 \mathrm{c}$ ). The proportion believing that the ban made it easier to quit reached a low, at $10 \%$, three months after the ban came into force, but appears to have been gradually rising since that time.

\section{Prevalence}

The implementation of the legislation caused no immediate significant change in smoking prevalence ( $\mathrm{p}=0.41$; estimate of effect -0.171 [95\% CI -0.580 to 0.237 ]; Figure $2 \mathrm{~d}$ ).

Youth surveys

Of the 214 teenagers interviewed pre-legislation, 180 (84\%) were successfully followed up and were thus included in the analysis. The characteristics of those followed up were similar to those lost to follow up, and to the target population in most attributes, but tended to under-represent the more deprived groups (data not shown).

Ten per cent of teenagers reported being current regular smokers pre-legislation, less than $1 \%$ reported smoking but less than once a week, and a further $6 \%$ of teenagers reported having smoked in the past but not at the point of interview; by post-legislation, $10.5 \%$ of teenagers were reporting being current regular smokers, $3 \%$ reported smoking but less than once a week, and 5\% reported having smoked previously (Table 2). The increase in current regular smoking post-legislation was not statistically significant $(\mathrm{p}=0.90)$. 
Confidential draft - not to be cited to quoted

Table 2 Youth questionnaire responses pre \& post legislation, with effect sizes represented by odds ratios for post compared to pre-legislation responses from conditional logistic regression

$\begin{array}{lll}\begin{array}{l}\text { Pre-legislation } \\ \mathbf{n}=\mathbf{1 8 0}\end{array} & \begin{array}{l}\text { Post-legislation } \\ \mathbf{n}=\mathbf{1 8 0}\end{array} & \begin{array}{l}\text { OR post compared } \\ \text { to pre-legislation } \\ (\mathbf{9 5 \%} \mathrm{CI})\end{array}\end{array}$

Current regular smoker $(>1 /$ wk or more)

No

Yes

If you try to buy, likely to be successful?**

Yes

No

Don't know

No. out of 100 children your age who smoke weekly?***

21-100

$0-20$

Don't know

In last month, recall seeing tobacco displays in shops? **

Yes

No

Don't know

Will removing cigarette/tobacco packs from view make it easier not to smoke?**

Easier

No difference

Don't know

$\begin{array}{lll}57(31.8 \%) & 45(25.2 \%) \\ 106(59.1 \%) & 121(67.2 \%) \\ 16(9.1) & 14(7.6 \%)\end{array}$

$0.61(0.34,1.09)$

\} Reference
Reference

$1.10(0.24,4.98)$

$\mathrm{p}=0.90$

$$
\mathrm{p}=0.10
$$

$\begin{array}{lllll}112(62.3 \%) & 82(45.5 \%) & 0.30(0.16,0.57) & \mathrm{p}<0.001 \\ 56(31.2 \%) & 78(43.3 \%) & \\ 12(6.5 \%) & 20(11.2 \%) & \text { Reference } & \end{array}$

\begin{tabular}{|c|c|c|}
\hline $146(81.4 \%)$ & $40(22.3 \%)$ & $0.05(0.02,0.14)$ \\
\hline $28 \quad(15.4 \%)$ & $131(72.7 \%)$ & Reference \\
\hline
\end{tabular}

$\begin{array}{lllll}84 & (46.8 \%) & 69(38.1 \%) & 0.62(0.36,1.04) & \mathrm{p}=0.07 \\ 82 & (45.3 \%) & 88(48.7 \%) & \} \text { Reference } & \\ 14 & (7.9 \%) & 24(13.2 \%) & \end{array}$

** 'No' (or no difference) and 'Don't know' responses combined for logistic regression analysis. OR is therefore the odds of responding 'Yes' post compared to pre-ban.

*** ' $0-20$ ' and 'Don't know' combined, for logistic regression analysis. OR is therefore the odds of responding '21-100' post compared to pre-ban.

Recall of seeing cigarette or tobacco display in shops in the last month dropped from over $80 \%$ of teenagers pre- to $22 \%$ post-implementation $(p<0.001)$. Other changes were that the percentage of teenagers thinking that they, or children of their age, would be successful in buying tobacco dropped from $32 \%$ before the law to $25 \%$ afterwards, though this difference was of borderline statistical significance $(p=0.10)$. The proportion thinking that more than $20 \%$ of children their age smoked decreased significantly from $62 \%$ before to $45 \%$ after the legislation was implemented $(p<0.001)$.

After the legislation, $38 \%$ of teenagers thought the ban had made it easier for children not to 
Confidential draft - not to be cited to quoted

smoke. This figure was slightly, but not statistically significantly, lower than the percentage who thought that removing point of sale displays would make it easier for children not to smoke pre-legislation $(47 \%, p=0.07)$.

\section{Discussion and conclusions}

This research has demonstrated that the removal of point of sale displays in Ireland was largely effective at removing cigarette and tobacco packs from view. A retail audit carried out within two months of the new legislation coming into force found $97 \%$ compliance with the law pertaining to removal of displays. Less than half the proportion of adults who reported seeing cigarette or tobacco packs for sale prior to the legislation, reported seeing them after the law was implemented. The drop was greater among youth, where just over a quarter of those reporting seeing tobacco packs for sale prior to the legislation, reported seeing them after implementation of the law. The law appeared to be effective at de-normalising smoking, at least in the short term: as evidenced by decreases in the proportion of children thinking that more than $20 \%$ of teenagers smoke. Over a third of teenagers, nearly two months after the legislation, thought that removal of the displays had made it easier for children not to smoke.

This study has several limitations. The Public Health (Tobacco) Acts 2002 to 2009 legislation removed point of sale displays alongside removal of point of sale advertising as detailed above. The survey questions were very specific and asked about tobacco pack displays but it is possible that the removal of point of sale advertising also impacted on the responses made by the adults and youth in our surveys. The effects of the removal of point of sale promotional displays could be confounded by other tobacco control measures introduced in recent years, although apart from the smoke-free legislation introduced in 2004, the only other major policies implemented were annual tax increases on tobacco products (averaging 0.39 Euro increase annually over the last four years) and a ban on packs of ten cigarettes at the end of May 2007. Both the adult and youth research utilized quota sampling techniques which may have introduced bias. Finally, only short term impacts of the legislation were measured and it is possible that results would be different if followed up after a longer spell post legislation. This is particularly pertinent for the youth study where a very short timescale elapsed before follow up, and together with the small sample size involved, indicates that these findings should be seen as preliminary. Larger samples of youth should be studied over long time periods to allow for seasonal effects such as greater initiation during summer months[26] to be taken into account.

Removals of point of sale promotional displays are introduced predominantly to protect children from the pernicious effects of tobacco advertising.[27] In support of this premise, it is noteworthy that a greater proportion of youth $(81 \%)$ reported seeing the packs before the legislation compared with adults (49\%) and there was a greater decline in recall of seeing tobacco packs post legislation among youth compared to adults. Concerns that point of sale displays contribute to the perception that tobacco products are normal consumer products, appear to be corroborated here. The removal of point of sale promotional displays contributed to a de-normalisation of tobacco as evidenced by declines in the proportion of children 
believing that they, or their peers, would be able to purchase tobacco successfully and in the proportion thinking, erroneously, that more than $20 \%$ of teenagers smoked. Although we cannot tease out the extent to which these changes are due to the removal of point of sale displays, point of sale advertising or vending machines, they suggest that measures to reduce visibility of tobacco products and their marketing are effective at denormalising smoking.[28, 29] Furthermore, after the legislation, 38\% of teenagers thought the removal of point of sale displays had made it easier for children not to smoke, although this proportion was smaller than the $47 \%$ believing this before implementation.

There was minimal effect of the legislation on adult smoking prevalence in the twelve months after the ban was introduced. Removal of point of sale displays is not hypothesised to have an immediate impact on smoking prevalence (see Figure 1); we believe that this is likely to manifest itself in enhanced quit rates among smokers and reduced smoking prevalence and sales over a longer time scale largely because of the addictive nature of smoking and the fact that many smokers who want to stop frequently make several unsuccessful attempts before eventually succeeding. Although the proportion of adult smokers thinking that removal of tobacco displays made it easier to quit smoking decreased slightly post legislation, nevertheless, in December 2009, six months after its implementation, nearly one in five smokers reported that the ban had made it easier to quit smoking. This finding supports other studies which suggest that the presence of cigarette pack displays makes it more difficult for smokers to quit.[30]

The removal of point of sale promotional displays was a popular measure being supported by the majority of adults both before and after implementation, with a slight increase over time. This is similar to findings of other research that, in general, tobacco control measures are popular, even among smokers, and support tends to increase over time.[31,32]

It is of some concern that even after the law was implemented, just under a quarter of adults and youth reported seeing tobacco packs for sale. It is unclear where they are seeing these displays as the audit confirmed that almost all retailers were compliant with the law, consistent with findings from other countries.[33] Small independent retailers had the highest level of non-compliance at 5\% which is a possible source.[22] Alternatively, or in addition, it could be that people are reflecting the fact that they are shown a pack during the sales transaction; cigarette sales were still possible through vending machines and although no advertising was allowed, it is possible that these were a source of their recollections. Perhaps also, some adults were mistaken and thought they had seen tobacco packs, but were actually remembering what stores were like prior to the ban. Further research to check this again over a longer time period and to ask where they saw the displays would be interesting.

The Framework Convention on Tobacco Control [34] recommends that the display of tobacco products at points of sale be prohibited and the evidence from Ireland indicates, for the first time, that implementing the removal of point of sale promotional displays is feasible on a national scale. The removal of point of sale displays is being challenged by the tobacco industry worldwide, for a variety of reasons [35] and this probably belies the importance of these 
Confidential draft - not to be cited to quoted

displays in its marketing efforts. The experience in Ireland, of mounting a legal challenge and then withdrawing it as it was about to come to court, suggests that the motives behind such cases are to deter other countries from adopting similar legislation and ensuring time and financial resources of regulators and governments are converted away from implementation and the development of new tobacco control laws. In Ireland it also had the effect of delaying the introduction of other aspects of planned legislative interventions while the court decisions were awaited.

In conclusion, removal of point of sale displays in Ireland was a mostly popular measure, including among smokers. At short term follow-up, the legislation appears to be contributing positively to the de-normalisation of smoking among children, and providing a more supportive environment for adults to quit and children not to smoke. In our view, any measure, that appears to be having positive impacts on deterring smoking among children and which a significant proportion of young people themselves perceive to be supportive of non-smoking, should be implemented in other jurisdictions without delay.

What is already known on the subject?

- Point of sale promotional displays remain one of the main channels for tobacco marketing following tobacco advertising bans

- Industry documents clearly spell out the importance of point of sale for marketing

- Survey data and experimental research have shown that point of sale promotional displays increase susceptibility to smoking and uptake of smoking among youth

- There is very little published in peer reviewed literature assessing the impact of point of sale removal

What this paper adds

- This paper reports short term impacts of legislation which, inter alia, removed point of sale tobacco advertising and displays in Ireland, implemented on 1 July 2009 following a protracted challenge involving the leading tobacco companies in Ireland (which they dropped just prior to coming to court)

- Compliance with the law was very high and recall of displays dropped significantly among adults and teenagers post-legislation

- The law was well supported among adults

There were encouraging signs that the law helped to denormalise smoking among youth and provide a more supportive environment for adults to quit and children not to smoke 


\section{Funding}

We are grateful for funding from the Office of Tobacco Control (OTC) Ireland, Cancer Research UK, the Irish Cancer Society (ICS), and ASH New Zealand to support this research and analysis.

\section{Acknowledgements}

We are grateful to Adam Crosier,Yilu Chen and Lisa Szatowski for their contributions to data collection and analysis and to Marie Killeen and Shane Allwright who commented on an earlier draft of this manuscript. We are also grateful to Ipsos mori for carrying out the research.

The Corresponding Author has the right to grant on behalf of all authors and does grant on behalf of all authors, an exclusive licence (or non exclusive for government employees) on a worldwide basis to the BMJ Publishing Group Ltd and its Licensees to permit this article (if accepted) to be published in Journal Tobacco Control editions and any other BMJPGL products to exploit all subsidiary rights, as set out in our licence (http://group.bmj.com/products/journals/instructions-for-authors/licence-forms) 
Confidential draft - not to be cited to quoted

\section{References}

1. Wakefield MA, Terry-McElrath YM, Chaloupka FJ, Barker DC, Slater SJ, Clark PI, Giovino GA. Tobacco industry marketing at point of purchase after the 1998 MSA Billboard Advertising Ban. American Journal of Public Health 2002;92:937-40.

2. Dewhirst T. POP goes the power wall? Taking aim at tobacco promotional strategies utilized at retail. Tobacco Control 2004;13:209-10.

3. MacGregor J. Tobacco Advertising at Point of Sale (Report to ASH) MacGregor Consulting Ltd., August 2008.

4. Rooke C, Cheeseman H, Dockrell M, Millward D, Sandford A. Tobacco point-of-sale (PoS) displays in England: a snapshot survey of current practices. Tob Control online first doi:10.1136/tc.2009.034447.

5. Cohen JE, Planinac LC, Griffin K, Robinson DJ, O’Connor SC, Lavack A, Thompson FE, DiNardo J. Tobacco promotions at the point of sale: the last hurrah. Can J Public Health 2009; 99(3):166-71.

6. Lovato CY, Hsu HC, Sabiston CM, Hadd V, Nykiforuk CI. Tobacco point-of-purchase marketing in school neighbourhoods and school smoking prevalence. Can J Public Health 2007;98(4):265-70.

7. John R, Cheney MK, Azad MR. Point-of-Sale Marketing of Tobacco Products: Taking Advantage of the Socially Disadvantaged? J Health Care Poor Underserved 2009;20(2):489-506.

8. Lavack AM, Toth G. Tobacco point-of-purchase promotion: examining tobacco industry documents. Tobacco Control 2006;15:377-384.

9. Pollay RW. More than meets the eye: on the importance of cigarette retail merchandising. Tobacco Control 2007;16:270-4.

10. Wakefield M, Germain D. Adult smokers' use of point-of-sale displays to select cigarette brands. Aust N Z J Public Health 2006; 30:483-4.

11. Wakefield M, Germain D, Henriksen L. The effect of retail cigarette pack displays on impulse purchase. Addiction 2008;103:322-28.

12. Carter OBJ, Mills BW, Donovan RJ. The effect of retail cigarette pack displays on unplanned purchases: results from immediate postpurchase interviews. Tobacco Control 2009;18:218-221.

13. Thomson G, Hoek J, Edwards R, Gifford H. Evidence and arguments on tobacco retail displays: marketing an addictive drug to children? NZ Med J 2008;11:87-98.

14. Paynter J, Edwards R. The impact of tobacco promotion at the point of sale: A systematic review. Nic Tob Res 2009;11:25-35.

15. Henriksen L, Schleicher NC, Feighery EC, Fortmann SP. A longitudinal study of exposure to retail cigarette advertising and smoking initiation. Paediatrics 2010;126:232-8. Epub 2010 Jul 19.

16. Joossens L, Raw M. The tobacco control scale. A new scale to measure tobacco control activity. Tobacco Control 2006;15:247-53.

17. McNeill A, Edwards R, Lewis S, Quinn S. Evaluation of the economic impact o the removal of point of sale tobacco promotional displays in Ireland. Submitted for publication. 
18. Edwards R, Thomson G, Wilson N, Waa A, Bullen C, O'Dea D, Gifford H. After the smoke has cleared: evaluation of the impact of a new national smoke-free law in New Zealand. Tobacco Control 2008; 17e2.

19. Haw SJ, Gruer L, Amos A, Currie C, Fischbacher C, Fong GT, Hastings G, Malam S, Pell J, Scott C, Semple S. Legislation on smoking in enclosed public places in Scotland: how will we evaluate the impact? J Public Health (Oxf) 2006;28:24-30.

20. Office of Tobacco Control. Tobacco Control and the Irish retail environment. OTC/tns mrbi.March 2008.Available at www.otc.ie/Uploads/OTC\%20Research\%20Report. pdf . Accessed 26 May 2010.

21. Office of Tobacco Control. National Tobacco Retail Audit - 2008 Monitoring Report. OTC/tns mrbi. February 2009.Available at www.otc.ie/Uploads/RetailAudit_2008MonitoringReport.pdf Accessed 26 May 2010.

22. Office of Tobacco Control. National Tobacco Retail Audit - 2009 Monitoring Report. November 2009. Available at www.otc.ie/Uploads/Monitoring-Report-2009.pdf . Accessed 26 May 2010.

23. Association of Market Research Organisations (AMIRO). A guide to social class grading on occupation (2005) Dublin, Ireland.Gavin A, O'Higgins S and the HBSC Ireland Team. Smoking behaviour among schoolchildren in Ireland. Health Factsheet 1. Available at: http://www.nuigalway.ie/hbsc/documents/fs_1_2006_july09.pdf

24. Office of Tobacco Control/Department of Health and Children. Guidance for those selling tobacco products. May 2009. OTC/DOHC, Co.Kildare and Dublin, Ireland.

25. Colwell B, Ramirez N, Koehly L, Stevens S, Smith DW, Creekmur S. Seasonal variations in the initiation of smoking among adolescents. Nicotine \& Tobacco Research 2006;8:239-43.

26. National Cancer Institute. The Role of the Media in Promoting and Reducing Tobacco Use. Tobacco Control Monograph No. 19. Bethesda, MD: U.S. Department of Health and Human Services, National Institutes of Health, National Cancer Institute. NIH Pub. No. 07-6242, June 2008.

27. Alamar B, Glantz SA. Effect of increased social unacceptability of cigarette smoking on reduction in cigarette consumption. American Journal of Public Health 2006;96:

1359-63.

28. Chapman S, Freeman B. Markers of the denormalisation of smoking and the tobacco industry. Tobacco Control. 2008;17:25-31.

29. Germain D, McCarthy M, Wakefield M. Smoker sensitivity to retail tobacco displays and quitting: a cohort study. Addiction 2009;105:159-63.

30. Action on Smoking and Health England. Beyond Smoking Kills: Protecting children, reducing inequalities. ASH, October 2008. www.ash.org.uk/beyondsmokingkills. Accessed 26 May 2010.

31. Fong GT, Hyland A, Borland R, Hammond D, Hastings G, McNeill A, Anderson S, Cummings M, Allwright S, Mulcahy M, Howell F, Clancy L, Thompson ME, Connolly G, Driezen P. Reductions in tobacco smoke pollution and increases in support for smoke-free public places following the implementation of comprehensive smoke-free workplace legislation in the Republic of Ireland: Findings from the ITC Ireland/UK Survey. Tobacco Control Supplement. 2005; 15:iii51-iii58. 
Confidential draft - not to be cited to quoted

32. Dubray JM, Schwartz RM, Garcia JM, Bondy SJ, Victor JC. Vendor compliance with Ontario's tobacco point of sale legislation. Canadian Journal of Public Health, 2009;100:2. http://journal.cpha.ca/index.php/cjph/article/view/1765/1949

33. WHO Framework Convention on Tobacco Control. Guidelines for implementation of Article 13. Available at: http://www.who.int/fctc/guidelines/article_13.pdf Accessed 16 August 2010.

34. Baker R. Tobacco brands challenge display ban. Marketing Week. 27 April 2010. Available at:

http://www.marketingweek.co.uk/news/tobacco-brands-challenge-display-ban/3012712.art icle Accessed 16 August 2010. 
Confidential draft - not to be cited to quoted

Figure 1 Logic model for evaluation of legislation to remove point of sale promotional displays

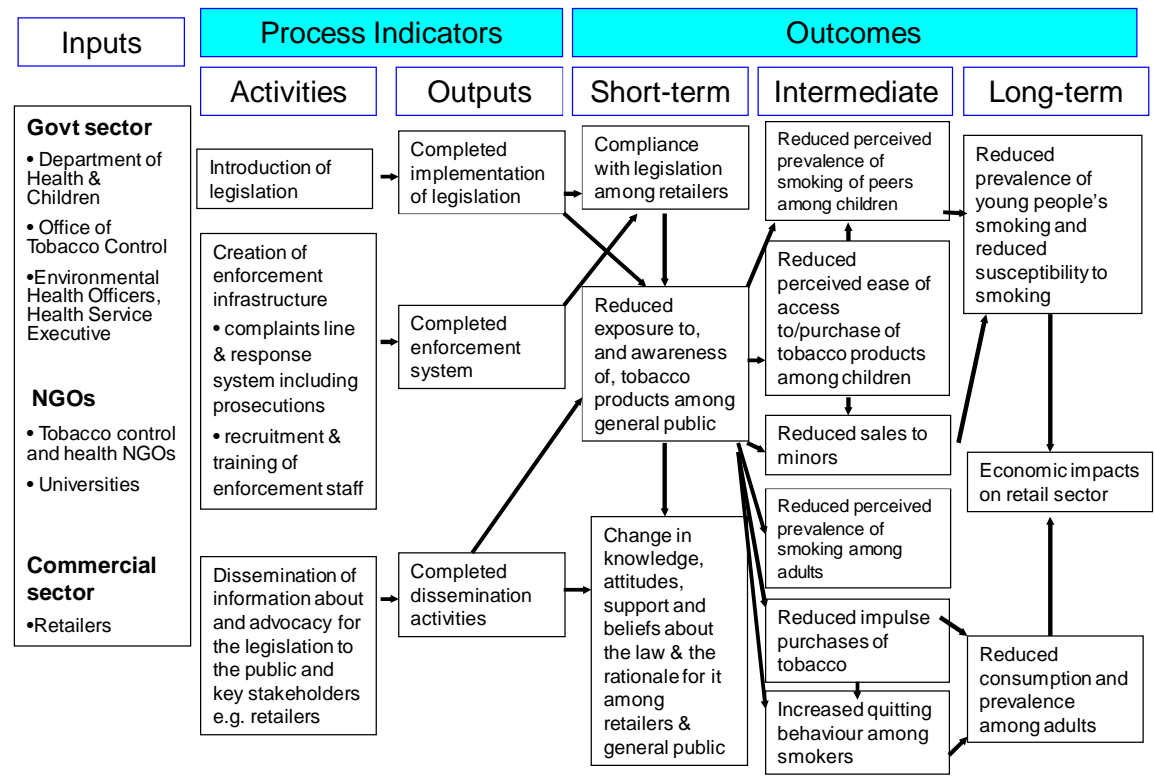


Confidential draft - not to be cited to quoted

Figure 2 Trends in recall, attitudes and behaviour among adult smokers

a. Recall of cigarettes/tobacco display in shops in the last month among adults, overall and according to smoking status

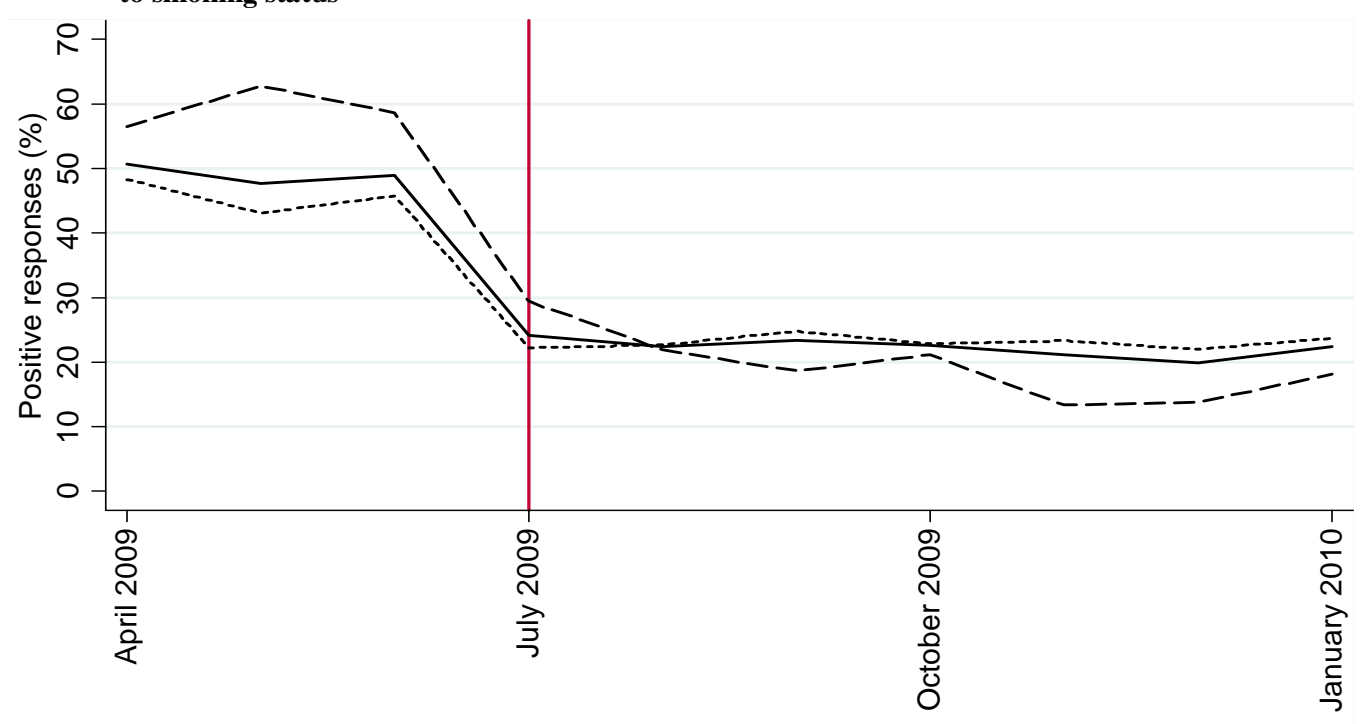

Month and Year

$\begin{array}{ll} & \text { all } \\ \ldots \ldots & \text { nonsmokers }\end{array}$

b. Support for a complete ban on tobacco displays among adults, overall and according to smoking status

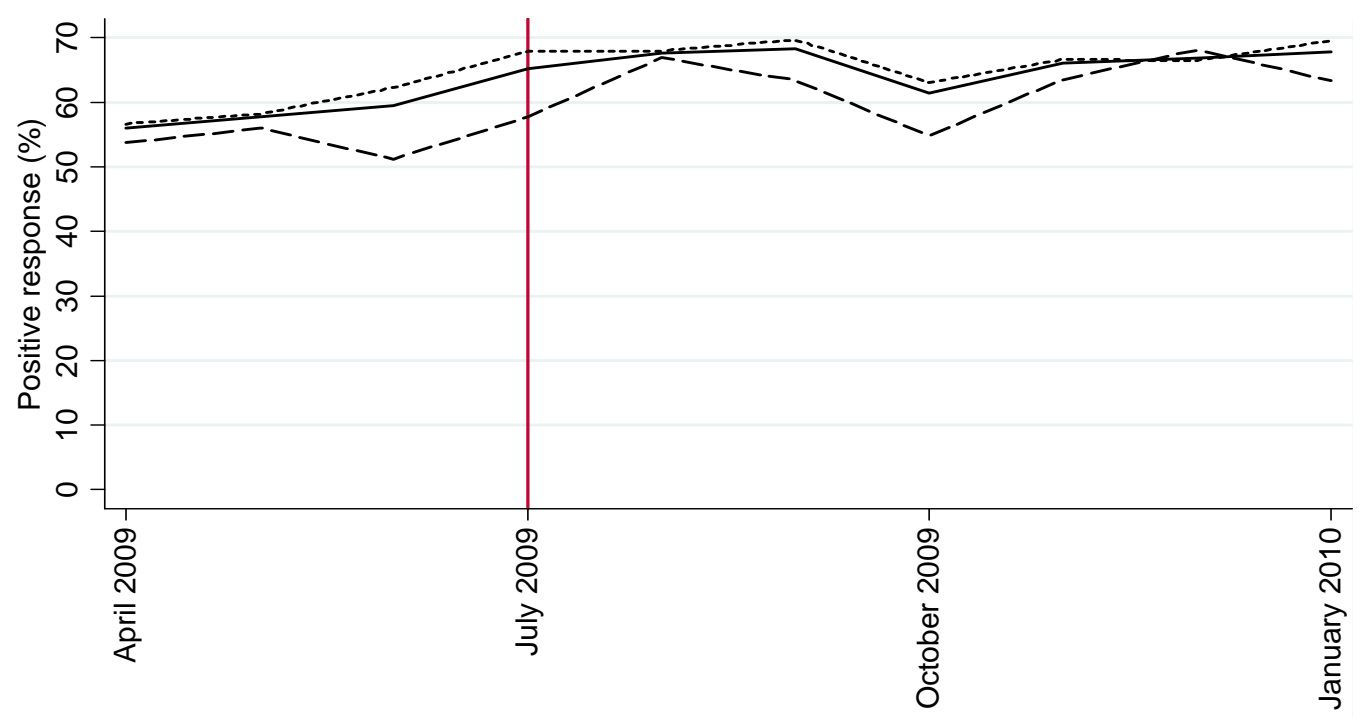

Month and year

\begin{tabular}{|ll}
\hline & all \\
$\ldots \ldots \ldots$ & nonsmokers
\end{tabular}

c. Perceptions of the effect of the legislation on quitting smoking among adult smokers 
Confidential draft - not to be cited to quoted

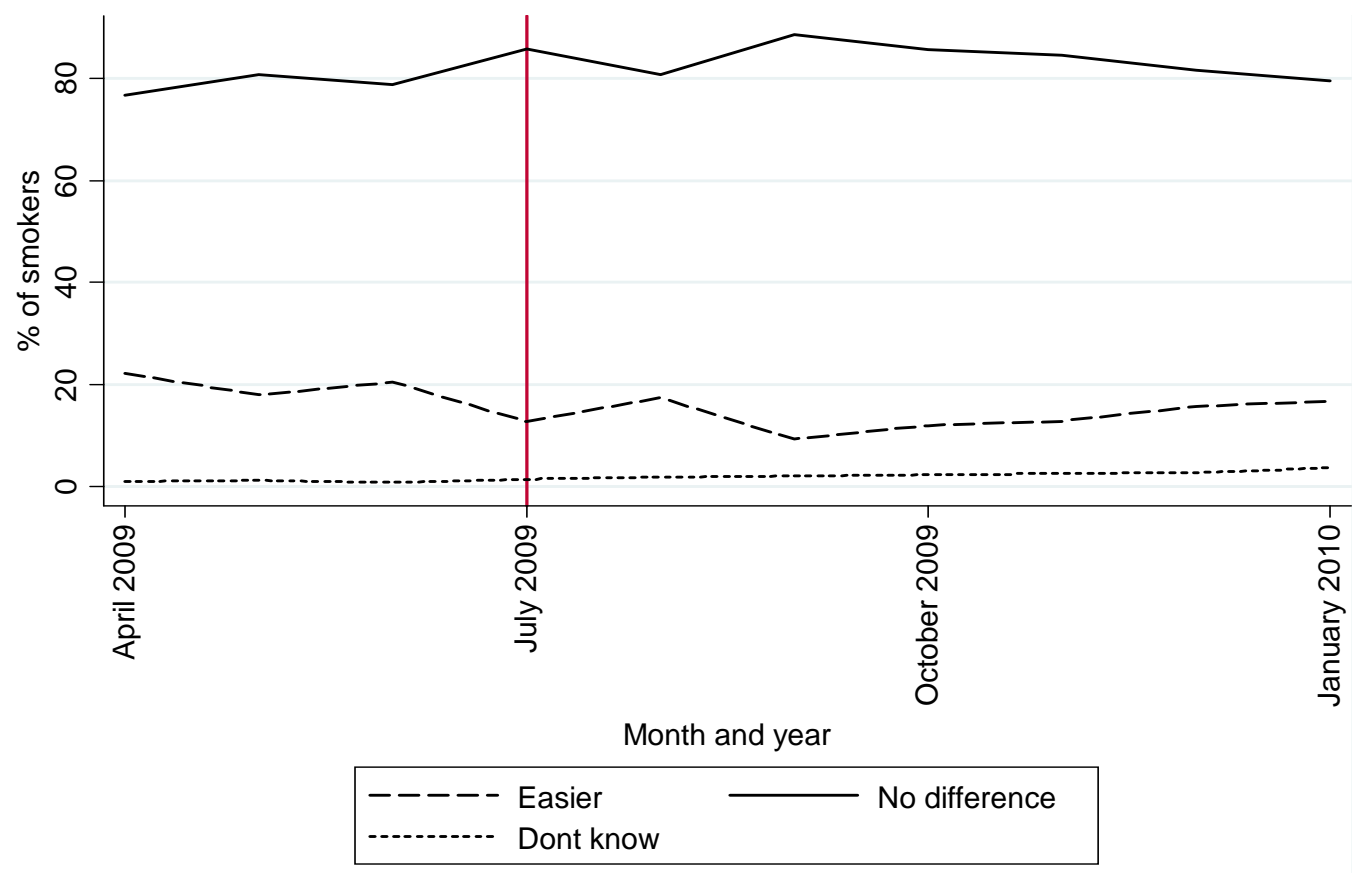

d. Trends in prevalence of current smoking ( 1 or more cigarettes per week)

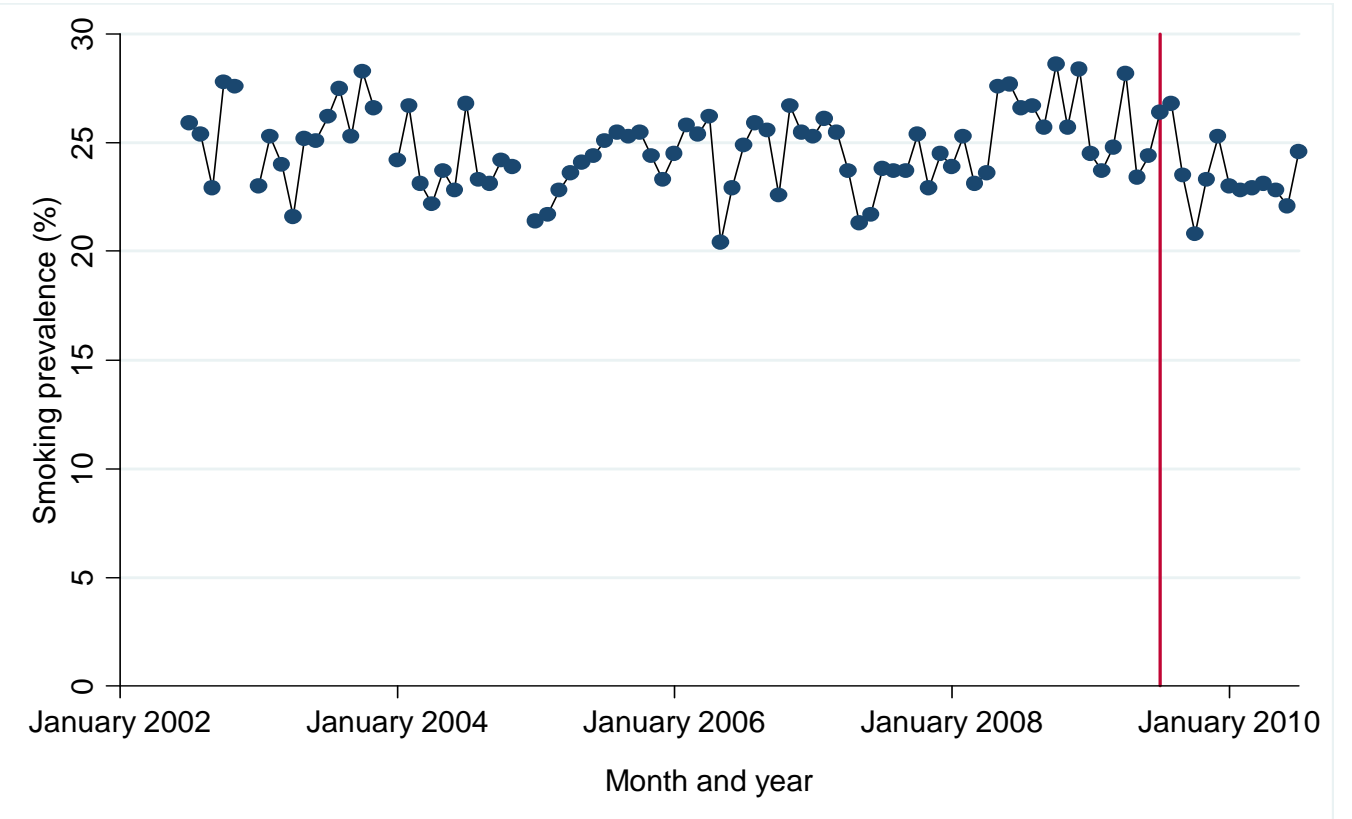


Confidential draft - not to be cited to quoted 